\title{
AGENCY-BASED VIEW OF LEARNING WITHIN THE MULTINATIONAL CORPORATION
}

\author{
Ayse Saka-Helmhout \\ University of Surrey \\ a.saka-helmhout@surrey.ac.uk
}

\begin{abstract}
Organizational learning within the international management field is commonly understood as knowledge transfer. Context-based and actor-centred investigations into the aspects of the social system that shape the learning process have received less attention. This study highlights the role of agency as embedded in MNC coordination networks where knowledge is distributed across a social system to account for non-isomorphic patterns of learning. It points to the social dimension of MNC learning by explicating actors' responses to acquired knowledge. The study is based on case studies that systematically compare the ways in which parent company knowledge diffuses to subsidiaries in the European chemical industry. It concludes that learning within multinational corporations is shaped by actors' orientation to drawing on the past, the present, and the future to inform their current practice beyond knowledge transfer.
\end{abstract}

Descriptors: Organizational learning, agency, knowledge transfer, multinational corporations 


\section{INTRODUCTION}

The social perspective on organizational learning has been widely canvassed outside the international management literature (e.g. Lave, 1993; Brown \& Duguid, 1991). However, the view of organizational learning in international settings is commonly a structuralist one, where learning refers to a process of transferring discrete best practices (e.g. Macharzina et al., 2001; Uhlenbruck et al., 2003). Organizational learning within the multinational corporation (MNC hereafter) is typically understood as knowledge flowing across industries and countries in a form abstracted from the wider social networks that leads to firm survival and effective performance (e.g. Zahra et al., 2000). Context-based investigations into the aspects of the social system that shape the learning process in international settings have received less attention (see review of debates by Easterby-Smith et al., 1999; exceptions include Hong et al., 2006). To conceptualize learning in international settings as knowledge transfer severely limits the role of human agency and projects learning as an isomorphic process that leads to similar patterns of learning across foreign subsidiaries. Whereas, learning as an agency-based activity highlights actors' recognition, location, and implementation of knowledge in their ongoing and situated transactions, and grounds individual and collective activities in the past, the present and the future (see Elkjaer, 1999). Consequently, the objective of this paper is to highlight the role of agency as embedded in MNC coordination structures where knowledge is distributed across a social system to account for non-isomorphic patterns of learning. We adopt an actor-centred account of organizational learning by explicating actors' orientations to enacting acquired knowledge.

Organizational learning in international contexts is discussed in the following section as an agency-based, situated activity. This is followed by the introduction of the method and empirical setting. The findings of the exploratory study that examines the learning patterns at Polish, Italian and German subsidiaries of a British and a German MNC in the chemical industry are presented in the fourth section. The final section presents the implications of introducing an agency-based understanding of learning for research on the multinational firm.

\section{THEORETICAL BACKGROUND Organizational Learning}

In line with the current line of thinking in the mainstream organizational learning literature (e.g. Cook \& Brown, 1999; Nicolini et al., 2003), we are critical of the focus on learning as individual acquisition of knowledge that reflects abstract thinking. In keeping with contemporary work on learning that is perceived as taking place through participation in communities-ofpractice (Lave \& Wenger, 1991; Wenger, 1998) or based on practice (e.g. Gherardi, 2000), we conceptualize organizational learning in international contexts as consisting of two aspects: i) the direction of knowledge flow, and ii) the actor's orientation to acquired knowledge. In this section, these two constructs that serve as the unit of analysis are presented. This distinction is in accordance with Brown \& Duguid's (1991), and Lave \& Wenger's (1991) understanding of learning through practice, where 'knowledge flow' represents abstract knowledge or canonical practice, and 'the actor's orientation to acquired knowledge' reflects actual or non-canonical practice. The distinction is also reflective of Elkjaer's (2004) synthesis of learning as acquisition of knowledge and learning that takes place as participation through a social process that addresses the 'what' and the 'how' of learning.

\section{The direction of knowledge flow}

Within the international management field, it is widely acknowledged that knowledge transfer presents opportunities for learning at both the subsidiary and the corporate level (e.g. 
Bartlett \& Ghoshal, 1989; Kogut and Zander, 1993). In fact, knowledge transfer is commonly used as a proxy for organizational learning (e.g. Macharzina et al., 2001; Uhlenbruck et al., 2003). We argue here that, for learning to be claimed, knowledge upon its transfer has to be manifested in human activity, for learning is a practical rather than simply a cognitive process that is shaped by an active process of participation in social processes (Elkjaer, 2004).

Knowledge flow in international settings is defined as the transfer of previously existing knowledge from one inventor to another for use in the creation of new knowledge (Yamin, 2004). It can flow either one-way from the parent to the subsidiary or two-ways between the parent and subsidiary. An example of a one-way flow of knowledge can be an MNC that operates with a global strategy (Bartlett \& Ghoshal, 1989). Global companies with centralized hub structures see the diversity of international environments as an inconvenience whose effect must be minimized. Their practices tend to be closely mirrored in subsidiaries (see Bird et al.'s exportive model, 1999). However, transnational companies (Bartlett \& Ghoshal, 1989) can be expected to encourage reverse transfer of knowledge from subsidiaries owing to their sensitivity to local market needs. Such subsidiaries in turn would have the potential to enhance the local responsiveness, global integration and worldwide learning capabilities of the MNC (Birkinshaw, 1997). This understanding of learning in the international management literature-what Elkjaer (2004) labels as the metaphor of acquisition-indicates that the direction of knowledge flow has implications for the ability of an MNC to learn. However, it does not capture the participation patterns that produce knowledge. We outline below the importance of the social dimension of MNC learning by highlighting actors' orientation to acquired knowledge.

\section{Actors' orientation to acquired knowledge}

Learning is perceived here as being realized upon the action that the acquirer assumes towards transferred practices. This involves agency or the ability to remember the past, imagine the future, and respond to present circumstances (Emirbayer \& Mische, 1998). Howard-Grenville (2005) summarizes such agency as actors' orientations that take the form of i) iteration, that is drawing from past artefacts, ii) application, that is pragmatically adopting artefacts to respond to the present situation at hand, and iii) projection, that is imagining or planning new uses of artefacts for the future. The iteration and pragmatic application of artefacts by actors do not involve any fundamental change to the nature of activities. They represent learning efforts directed at simple maintenance or elaboration of existing routines for efficiency and effectiveness (Hendry et al., 1995). By contrast, actors' orientation towards future aspirations, i.e. projection, reflects learning efforts directed at changing routines for a new orientation to work (ibid.). Artefacts refer here to knowledge repositories such as product ideas, marketing and manufacturing knowledge that are transferred in the form of canonical documentation, training, or personal experience (see Hong et al., 2006). They can be of technical (defined as new techniques without major change to behaviour) or systemic (defined as new procedures and systems with behavioural consequences) nature (Child, 1994).

\section{METHOD}

The research is based on comparative case studies of learning in two large MNCs with operations in Italy, Germany, and Poland. One of the MNCs in the sample, British Chem (a pseudonym), is an internationally operating chemical company that was founded in the early 1900s in the UK. It emphasizes research and development, and the production of decorative paint. The second MNC, German Chem (a pseudonym), is an internationally-operating chemical company that was established in Germany in the late 1800s. The unit on which this study is based 
produced cleansing agents for domestic use. The study aimed to investigate the processes whereby artefacts were enacted by actors within a given MNC coordination structure to generate a particular pattern of organizational learning.

The selection of the subsidiaries was based on their network membership, which either reflected the integrated network or the international typology. These models were identified along the dimensions of i) the extent to which capabilities and decision-making were decentralized, ii) the extent to which control was exercised through indirect, implicit means, and iii) the extent to which there existed high interdependency of work between the subsidiaries and headquarters (see Bartlett \& Ghoshal, 1989; Harzing, 1999). As this information was not readily available in the public domain, we relied on the judgement of two strategic managers (VP of Operations at the British MNC, and Strategic Planning Director at the German MNC) in our initial interviews. These interviews revealed that although there was a shift in the industry towards global integration of operations, the two MNCs operated different coordination models. In the late 1990s, British Chem, facing pressure to maximize returns on a single project, adopted an international strategy. This shift brought with it formalization, particularly in product development, where subsidiaries were primarily regarded as appendages to a central domestic corporation. Similarly, given competitive pressures to improve profitability in mid-1990, German Chem adopted a mix of transnational (among Western European (WE) sites) and global strategy (among Central Eastern European (CEE) sites) to operating outside the domestic market. In other words, there was an emphasis on specialized operations and interdependent relations among WE operations. Whereas, CEE operations were managed centrally by Austria (the CEE HQ), and granted less autonomy than WE operations. For instance, they were not involved in new product development.

Both MNCs were located in the chemical industry with a flow production process. The industry was characterized by high levels of internationalization and innovativeness (CEFIC, 2001), which deemed it suitable for investigating organizational learning within the MNC context. The research examined the enactment of acquired marketing, manufacturing, and product-related artefacts such as product formulations.

Case studies (see table 1), employing 31 interviews, were carried out between March 2002 and May 2003 with executives overseeing international operations in marketing, manufacturing, human resources and $\mathrm{R} \& \mathrm{D}$ at headquarters and their counterparts at subsidiaries, as well as factory tours and document analyses of annual reports. All interviews were taped and transcribed. Information was collected from respondents on: the types of practices that were transferred, resources that were made available by headquarters, the role of headquarters in subsidiary's operations, procedures that were adopted by headquarters for participation by the subsidiary members in new product development, and the adaptation of products to the local market.

Table 1 about here

The reliability of the findings was enhanced by making explicit the procedures that were followed for data collection. These procedures included matters of interview protocol, tape recordings of interviews and feedback on transcriptions from participants. Within case companies, interview data from a particular work group such as $R \& D$ were checked against responses from another group such as marketing to validate findings (see Table 2 for a list of interviewees). These groups were identified along functional lines. For instance, the emphasis on exporting product 
ideas to subsidiaries by R\&D members was checked against the responses of marketing members at British Chem HQ. Similarly, subsidiary and headquarter members' accounts were crosschecked against each other. Interview transcriptions were scanned to identify actors' orientations to transferred artefacts at subsidiary firms, as well as the 'bundles of conditions' that accounted for the variation in these orientations.

Table 2 about here

As the British MNC had an insignificant manufacturing operation of small volume in Italy, it was not possible to perform a direct comparison of learning patterns across the Italian subsidiaries. Thus, the two significant manufacturing operations of the British MNC-German and Polish-were compared with the Italian and Polish subsidiaries of the German MNC.

The direction of knowledge flow was categorized as one-way where there was exporting alone of knowledge from the headquarters to the subsidiary. Two-way flow of knowledge took the form of exporting and importing of product concepts and formulations by the headquarters. Actors' orientation was categorized as projection where subsidiaries assumed a proactive role in improving their market position or fighting local competition by for instance introducing a new product idea. The orientations of iteration and application were resonated in subsidiaries' efforts respectively to resist new product ideas and to instigate incremental change in processes such as adapting raw materials in product formulations without fundamental change to business objectives.

Selecting similar MNCs operating in the same industry ruled out any variation in MNC and industry characteristics such as age and competition that could explain for possible differences in learning patterns. Such sampling was essential as the research aimed to highlight the situatedness of learning in social processes such as coordination and control rather than in economic conditions or what Harzing and Sorge (2003) refer to as universal contingencies that are decoupled from nationally-specific institutions. Although there was variation in the types of products manufactured, both MNCs operated a flow-production process. Thus, the industry recipes were similar.

Initially, detailed case studies were conducted that captured contextualities in learning such as the type of coordination structures that the MNCs adopted towards their subsidiaries. This was followed by a comparison across cases conducted systematically using Mill's (1974) rigorous method to allow for theoretical generalization. Mill's 'method of difference' was adopted for comparing cases with different learning patterns. In other words, an instance of a phenomenon's occurrence was compared with an instance of its non-occurrence to identify 'bundles of conditions' that explained for the variation in outcome. This is a method of elimination based on the "successive exclusion of the various circumstance which are found to accompany a phenomenon in a given instance, in order to ascertain what are those among them which can be absent consistently with the existence of the phenomenon" (ibid., p. 392). It combines detailed case studies with systematic comparison. This method is similar to Eisenhardt's (1989) coupling of within-case data analysis with cross-case patterns for a more sophisticated understanding. However, it differs from Eisenhardt's method in its explicit aim to delineate patterns of regularities in microsociological phenomena embedded in historical contextual singularities across countries. It meets the challenge of dealing with both complexity of interactions and 
attaining causality in patterns of activities for generalisability as case studies increase in number as is commonly the case in cross-national studies.

\section{FINDINGS}

The case studies demonstrate that there is variation in actors' orientations owing to differences in coordination structures adopted by MNCs. The German MNC's efforts to create tight networks of relations between the headquarters and subsidiaries through socialization and corporate culture maintenance encourage two-way flow of knowledge and actors to engage in projection. However, what is more interesting to note is that British MNC's comparatively weaker coordination structure also encourages projection despite mainly one-way flow of knowledge from the headquarters to subsidiaries.

\section{Patterns of Learning at British Chem's Subsidiaries}

In spite of its local responsiveness to market differences in terms of packaging and colour range, British Chem mainly exports product ideas and recipes, indicating one-way flow of knowledge, to its European subsidiaries. "Knowledge is developed at the centre and exported to overseas units" (Strategic Research Manager, British Chem). Subsidiaries are responsible for minor changes to products.

For local development of products, usually that is best done very close to the customer in a local country, you know, you are putting few extra colours on to the colour range or just making a small change to a particular product...We do have a discipline, a template, an operating framework that says what is decided where, which decisions are to be taken locally, regionally, internationally and what things you need to tell people. (Research and Innovation Director, British Chem).

The rules, procedures and policies for new product development are standardized and formalized.

We are much better organized in terms of having country managers and functional structures, which are much more European-based. So in terms of R\&D, although we have some labs such as that in France and in Poland, our activities are all pretty well managed in terms of knowing what is going on and who is doing what... There are [links], whether they are solid or not, I would not like to say, some are solid some are dotted lines, but there is a lot of clarity. (General Manager, R\&D Europe)

Consistent with this change was the introduction of a continuous improvement programme at the operational level called Paint Plant of the Future across all sites in 2002. "On a global basis, our plants are significantly behind world class performance and therefore we need to raise the standards and performance of all our plants globally and try to give the momentum of everybody working together on a similar sort of agenda" (Senior VP of Operations, British Chem).

British Chem supported the development of its German subsidiary's (acquired in 1998) innovative capability by transferring manufacturing process improvement knowledge, via canonical documentation as well as technology needed to adapt product formulations developed at headquarters to raw materials in Germany. "The standards are clear. There are a set of metrics-conversion cost in pence per litre, operations efficiency of the packing lines, right-thefirst time to production, cycle times through the plant, and yield loss - that we strive to achieve (Dutch Managing Director at British Chem's German subsidiary). Unlike German Chem, British Chem did not emphasize the transfer of personal experience via expatriate management and international training. With limited attention given to the acculturation of subsidiary members, 
transfer of artefacts met resistance in both production and marketing functions. "Special practices such as quality management systems in the UK [at British Chem] are spread internationally to improve efficiency and quality. The knowledge that is being transferred from the headquarters has not changed anything fundamentally" (Senior Product Manager at British Chem's German site). "A mixture of people expressed that they liked the 'old way'. They were told to do it and they did it. They were used to hearing 'we will fix it for you"" (Dutch Managing Director at British Chem's German subsidiary). This translated into reactive maintenance, limited of use of data for continuous improvement, lack of discipline and urgency in shop-floor activities, in particular, in the filling area, and exceptions seen as problems. In addition, "there were cumbersome processes in introducing new products, hierarchical decision-making processes with long lines of communication, cumbersome sign-off processes, departmental interdependencies rather than an entrepreneurial style, and an 'it is not my problem' mindset" (Dutch Managing Director at British Chem's German subsidiary).

By the same token, there was a conservative attitude to acquiring product ideas from the headquarters.

With the [X brand], what we did is that we exported it from the UK. So they [the German subsidiary] took the same range as the UK, and then gradually over a period of time, we formulated a match using their raw materials... They sorted their factory out in terms of their quality. So they are now making it for themselves as well as for Czech and Hungary. (General Manager R\&D Europe, British Chem)

The idea of transferring the [X brand] to Germany initially met resistance: "Four years ago, when I discussed this with Germany and the UK, they [Germany] asked 'why do you want to launch this when other paints cover well, better than those of the competitors?"' (Marketing Director at the Polish subsidiary of British Chem). The product idea was later adapted to local raw materials. The German subsidiary was not too open to ideas transferred from its parent company owing to a pre-existing culture established prior to its acquisition by British Chem. It assumed a reactive orientation to improving its processes in continuous steps to meet HQ standards.

Because people used to be independent for 40 years in their history and all of a sudden there comes a parent company, puts a foot on us and says 'we will guide you through some of our standards. We have got company standards that you have to follow', people see that sometimes as pain. (Dutch Managing Director at British Chem's German subsidiary)

Old routines hampered the diffusion of knowledge and discouraged the materialization of new ideas. The German subsidiary adhered to old ways of working (i.e. engaged in iteration) and pragmatically adapted its products to the German market (i.e. engaged in application) rather than strategically reoriented.

Similar to the German subsidiary, there is one-way flow of knowledge such as product recipes to the Polish subsidiary (acquired in 1996). "All the recipes are owned, in fact, by the UK. So if we want to make changes to the recipes, those need to be approved by the UK. There are people from the UK labs who come here and advise" (Marketing Director at British Chem's Polish subsidiary). This is related to time and resource constraints such as the size of the R\&D department at the Polish site (Head of Research Lab at British Chem's Polish subsidiary). If the Polish site has an idea for a new product, its recipe can be prepared in Poland, the test results discussed with the parent company, and the product sold under the international brand name. However, despite the importation of product ideas from the headquarters, the Polish site assumes an active orientation based upon an anticipation of future market needs, i.e. engages in projection. There was no evidence of reverse diffusion of product ideas generated by the Polish subsidiary 
and adopted by HQ to be rolled out to other operations. This indicates that there is not necessarily congruence between knowledge flow and actors' orientation to transferred artefacts, highlighting the significance of studying the process of enactment beyond that of knowledge transfer.

In terms of the sophistication in the Polish market now...the paint companies have gone in and started to grow the market from a value point of view, getting them into colour, bringing innovation into the marketplace...They [the Polish] are responding much more readily than say the Germans did, who have perhaps been stuck in their way. (General Manager R\&D Europe, British Chem)

The subsidiary is receptive to new ideas from the headquarters. "They [the Polish subsidiary] are hungry for ideas. This is not to say they do not have good ideas of their own, but they are hungry" (General Manager for R\&D Europe, British Chem). It also "co-operat[es] in some projects concerning the future of solvent-borne products in Poland. We are also discussing NPD [new product development] regularly" (Polish R\&D Manager at British Chem's Polish subsidiary). Although the subsidiary is perceived as the least technologically advanced of all players in Poland, and "have probably the smallest and not probably the best equipped R\&D lab..., we could implement this [low-volume, highly profitable, value-added brands] during the preliminary phase of the launch on the market even without having all the stuff [technical capabilities] locally" (Marketing Director at the Polish subsidiary of British Chem).

The Polish subsidiary's proactive search for ideas in British Chem's pool of expertise opened up opportunities for new patterns of thinking about business objectives. As illustrated below, the company revised designs and manufacturing processes to lead the industry trend, actively engaging in change of a strategic kind.

About four years ago, we were looking at different products to launch which would be innovative, different and better than what the competition has got. There were no products...the market at that point in time seemed to be following the way of developing the tinting business...Looking at the UK market, there were suggestions that launching colours would not be a bad idea, because it works in the UK. However, we are afraid of advices of doing something because it works in the UK. So we did not really know which would be the preferred route. (Marketing Director at the Polish subsidiary of British Chem)

Market research results on another innovative product that pointed to important benefits to consumers encouraged the Polish site to launch colours. The subsidiary recast its strategy to raise its rank to a second position in the marketplace.

\section{Patterns of Learning at German Chem's Subsidiaries}

In line with the shift in international strategy in 1995, German Chem restructured its marketing units. "Now marketing units operate in Euro teams [which consist of a strategic business unit member from the headquarters and marketing managers across Europe]. The Euro team notion is quite important, because everybody is both a local manager and a member of a Strategic Business Unit (SBU) team of that function" (VP Market Research/Business Intelligence at German Chem). Euro meetings are steered by the German headquarters, and are held among the long-established WE subsidiaries of German Chem to stimulate new product development. They aid in forging interdependency among subsidiaries. In the context of the shift in international strategy, German Chem also offers cultural training that focuses entirely on tearing down national borders. It emphasizes 'strong corporate culture' and tries to ensure that its subsidiaries share the main values of the firm. This is carried out through the participation of subsidiaries in international management training for company-specific knowledge and emphasis on sharing 
personal experience via expatriate management. "You invest in a lot of infrastructure, not only machinery and equipment, but you build up very much in people, education, training" (Corporate VP Manufacturing at German Chem). "We are sending people to Germany in the form of job rotation...It may be a short period for training purposes and visits for exchange of experience between headquarters and local units" (R\&D Manager at German Chem's Italian subsidiary).

The participation of the Italian site (established in 1935) in the strong, tightly-knit network of Euro-team meetings encourages the importing and exporting of knowledge on product ideas. "We have the opportunity to participate directly in the work of the German Chem Group, developing new ideas directly" (R\&D Manager at German Chem's Italian subsidiary). The site is able to change fragrances and colourants, as well as viscosity levels of products upon lengthy negotiations with HQ. Proposals need to be approved by HQ before they can be introduced to the market.

We worked 10 years ago to re-launch formula with a new raw material. The reason was the bio-degradability of the old raw material. So an international team was established. We were part of this team. First studies were done in Germany. We then worked to adapt the process in Italy, France and Spain...High viscosity was very important for Italy, but not so important for other countries. So we had to find a way to increase the viscosity of the product having the same level of cost as in other countries. We followed a very precise process with specific parameters. The results were then sent to Germany" (R\&D Manager at German Chem's Italian subsidiary).

Strong test results convinced HQ to approve the project. By the same token, the Italian subsidiary has proactively taken the decision to introduce a marsiglia-based variant to fight competition in international brands, in particularly softeners. This has been strongly opposed by the parent company.

It is a huge trend for Italy. Marsiglia is a soap bar, which was used in the past, in the $20^{\text {th }}$ century, a soap used by my grandmother. It has a very characteristic odour. It is quite well known for being quite effective...It is cheap and environmentally friendly...About four to five years ago, we saw a trend in the detergents [among local producers] that were using this marsiglia soap as a marketing concept. It was an enormous success...We were the first to introduce it into dishwashing, then into softeners. Can you imagine into the softeners? It took us three to four years to convince Germany in this case that marsiglia was an interesting trend. (Product Manager at German Chem's Italian subsidiary)

The German headquarters did not want to adopt marsiglia, because they regarded it as a cheap, ineffective, bad-smelling product that would damage the image of their premium-branded goods. "In the beginning, the test results were not enough to sell to the top management that it was a good process, but then they realized that it was possible" (Product Manager at German Chem's Italian subsidiary). Such experimentation at the subsidiary indicates an orientation towards projection. Despite initial opposition from $\mathrm{HQ}$, the subsidiary initiates change proposals of a strategic nature. It also enables headquarters to benefit from local experiences. This is illustrated by the Italian subsidiary's local experience in physical behaviour of particle sizes in dispersion and shared stress: "We have this kind of experience and facility here, thus had more possibility than colleagues in Germany [HQ] or in Spain and France to perform trials. We also have experience in [Y brand] softener, because Lomazzo was one of the first plants to produce softeners in the [German Chem] Group" (R\&D manager at German Chem's Italian subsidiary). This suggests a two-way flow of knowledge on product recipes and formulations between the Italian subsidiary and the parent company. 
By contrast, there is no evidence of German Chem's importing of product ideas from its Polish subsidiary despite its operation in Poland since 1931. German Chem emphasizes the exporting of marketing techniques and technical tests to Poland, indicating one-way flow of knowledge from the parent to the subsidiary. "[A] lot of the marketing mix is developed in the [CEE] headquarters. And the countries are responsible for excellent execution of this initiative" (Austrian Marketing Manager at German Chem's Polish subsidiary). "95 per cent of the communication is always going through Austria. When Romania wants some information from Poland, they are asking us and we are asking Poland" (Brand Manager at German Chem's CEE HQ). New product development decisions are also taken at the headquarters.

A country can come and say it would be interesting to develop for example soap paste, which is still in use in countries like Romania. Then we get a proposal to develop such a product. But they do not develop it in their own country...because you need the background...I know in the HQ many persons for 17 years and know where they have started....So we [CEE HQ] have the networking advantage owing to the long history. (R\&D Manager at German Chem's CEE HQ)

The Polish subsidiary is simply responsible for preparing labels in accordance with the Polish law, registering detergents with the Polish authorities, and performing quality checks on locallyproduced goods (R\&D Manager at German Chem's Polish subsidiary). According to the headquarters, "there is mismanagement in the company. The company is not run properly. The investment is not there. State-of-the-art product cannot be made. There is good technology and highly skilled people available, but the whole system is totally bankrupt" (Corporate VP of Manufacturing at German Chem). There is an emphasis on bringing practices into the fold with those of the parent company whereby actors assume an orientation of iteration.

\section{DISCUSSION AND CONCLUSIONS}

Although the companies face similar global pressures to integrate their worldwide operations, there is divergence in their initiatives to encourage learning at subsidiaries. This hinges upon the specific international strategies of the two MNCs that are reflected in their coordination structures. The integrated network model adopted by the German MNC to coordinate its WE operations, which can be observed in its heavy emphasis on developing horizontal linkages and subsidiary capabilities, encourages two-way flow of knowledge. The coordination of subsidiaries in an international form by the British MNC encourages one-way flow of knowledge. However, the transfer of knowledge per se does not reveal how it is connected to changes in behaviour within the multinational community. The specificity of organizational learning lies in contextualizing knowledge through its link to enactment. The findings reported here indicate that the actors' orientation to iterate, apply and project artefacts and the specific coordination structure in which this is embedded influences patterns of learning at subsidiaries.

Table 3 provides an overview of the variation in learning patterns across the German, Italian, and Polish subsidiaries of the British and German MNCs.

Insert Table 3 about here

German Chem emphasizes the acculturation of its subsidiaries within the WE network through international transfer of managers and international training, what Harzing (1999) calls 
informal or indirect personal control. Such socialization aids in orienting actors' behaviour towards collective learning (Hong et al., 2006). German Chem's emphasis on expatriate management is evident in the number of HQ personnel assigned to various subsidiaries. For instance, there is a German Chem member working in the marketing department of the Italian subsidiary. It also encourages sharing of knowledge and experiences in Euro teams for new product development. These teams can be perceived as learning groups in which insights can be transformed into knowledge through mutual engagement around a joint enterprise (e.g. Soekijad et al., 2004). In comparison, despite their recent acquisition (see table 3), British Chem neither has headquarters personnel serving its German and Polish subsidiaries, nor provides technical international training for its subsidiary members. Rather, it chooses to standardize and formalize rules, procedures and policies to co-ordinate and control activities.

What is more interesting to note is that the international coordination structure of British Chem does not necessarily have negative implications for learning. Although this form of coordination would suggest that the greater dependence of subsidiaries on the centre for the diffusion of knowledge does not endow firms with much autonomy to develop knowledge (Bartlett \& Ghoshal, 1989), there is proactive orientation to product development at the Polish subsidiary. This is elicited by an understanding of learning as active participation in social processes whereby actors' orientations to putting acquired knowledge to practice are highlighted (see Howard-Grenville, 2005). In spite of the relatively centralized means of controlling product development - pressure that is felt by both the German and the Polish subsidiary-, there is flexibility at the Polish subsidiary within which practices can 'evolve' without headquarters' involvement. The Polish operation assumes an active role in searching for and adapting new product ideas to introduce to the market. For instance, the risk taken by the Polish subsidiary in launching colours in a market where the future was perceived to be in tinting business based on the market performance of an earlier-introduced idea shows strategic thinking oriented to the future. By contrast, the German subsidiary responds to product ideas and recipes in a reactive manner that is characterized by caution, inhibition, and an aversion to experimentation owing particularly to its rich administrative heritage, similar to German Chem's conservative attitude towards approving its Italian subsidiary's product ideas and supporting the development of its Polish subsidiary. These findings shed light on the national institutional effects on learning. Practices in German companies tend to be highly institutionalized in collaborative national business systems that support cooperation between collective actors (Whitley, 1999). Key labour market institutions of collective bargaining, co-determination and initial vocational training deem human resource management by a pluralistic style (Giardini et al., 2005). It is argued these highly institutionalized features of Germany restrict the implementation of foreign practices (e.g. Wever, 1995). By contrast, relations between actors in the UK national business system, labelled as compartmentalized, are defined as arm's length and typically adversarial (Whitley, 1999). There is emphasis on the reduction of agency costs through heavy reliance on formal mechanisms to order commercial relationships among transacting parties (Vitols, 2001). As competences are not constrained by obligational ties to partners as those in Germany, they tend to be more mobile across national borders (ibid.). Foreign subsidiaries (such as the Polish site in this study) of British firms can develop distinctive capabilities quickly as they are not constrained by high levels of MNC control.

Agency-based accounts of learning that recognize the link between knowledge and action in the international arena require more empirical research, particularly given the emphasis on international diversity as a significant determinant of MNC learning (e.g. Zahra et al., 2000). It is 
not sufficient to argue that learning which is disembodied from practice is fostered by diversity in experience and the differences between acquired and acquiring firms (e.g. Barkema \& Vermeulen, 1998). This study has highlighted the need to consider the link between knowledge flow and actors' orientation to acquired knowledge that is situated in MNCs' coordination and control activities for a more refined understanding of learning in international settings. Future research, in an effort to contribute further to studies on MNC learning, can shed light on the interactive and contentious nature of learning in different forms of national governance. This would address some of the failings in mainstream international business scholarship, as outlined by Redding (2005), in particular the privileging of context-free rational agency and the determinacy over subtle and less explored influences of history, context and social meaning systems.

\section{REFERENCES}

Barkema, H. and Vermeulen, F. (1998) 'International Expansion through Start-up or Acquisition: A Learning Perspective', Academy of Management Journal 41: 7-26.

Bartlett, C. and Ghoshal, S. (1989) Managing Across Borders: The Transnational Solution. Boston, Massachusetts: Harvard Business School Press.

Bird, A., Taylor, S. and Beechler, S. (1999) 'Organizational Learning in Japanese Overseas Affiliates', in S. Beechler and A. Bird (eds), Japanese Multinationals Abroad: Individual and Organizational Learning, pp. 235-59. New York: Oxford University Press.

Birkinshaw, J. (1997) 'Entrepreneurship in Multinational Corporations: The Characteristics of Subsidiary Initiatives', Strategic Management Journal 18: 207-29.

Brown, J. S. and Duguid, P. (1991) 'Organizational Learning and Communities-of-Practice: Toward a Unified View of Working, Learning, and Innovating', Organization Science 2: 40-57.

CEFIC (2001) Facts and Figures: The European Chemical Industry in a Worldwide Perspective. Brussels: The European Chemical Industry Council, www.cefic.org.

Child, J. (1994) Management in China During the Age of Reform. Cambridge: Cambridge University Press.

Cook, S. D. N. and Brown, J. S. (1999). 'Bridging Epistemologies: The Generative Dance Between Organizational Knowledge and Organizational Knowing', Organization Science 10: 381400.

Easterby-Smith, M., Burgoyne, J. and L. Araujo (1999). Organizational Learning and the Learning Organization: Developments in Theory and Practice. London: Sage Publications.

Eisenhardt, K. M. (1989) 'Building Theories from Case Study Research', Academy of Management Review 14: 532-50. 
Elkjaer, B. (1999). 'In Search of a Social Learning Theory', in M. Easterby-Smith, J. Burgoyne and L. Araujo (eds) Organizational Learning and the Learning Organization: Developments in Theory and Practice, pp. 75-91. London: Sage Publications.

Elkjaer, B. (2004). 'Organizational Learning: The "Third Way", Management Learning 35: 41934.

Emirbayer, M. and Mische, A. (1998) 'What is Agency?', American Journal of Sociology 103: 962-1023.

Gherardi, S. (2000). 'Practice-based Theorizing on Learning and Knowing in Organizations: Introduction to the Special Issue on Knowing in Practice', Organization 7: 211-23.

Giardini, A., Rüdiger, K., and Müller-Camen, M. (2005). "HRM in the German Business System: A Review", Management Revue, 16: 63-80.

Harzing, A.W. K. (1999) Managing the Multinationals: An International Study of Control Mechanisms. Cheltenham: Edward Elgar.

Harzing, A. W. K. and Sorge, A. (2003). 'The Relative Impact of Country of Origin and Universal Contingencies on Internationalization Strategies and Corporate Control in Multinational Enterprises: Worldwide and European Perspectives', Organization Studies, 24: 187-214.

Hendry, C., Arthur, M. B. and Jones, A. M. (1995) Strategy through People: Adaptation and Learning in the Small-Medium Enterprise. London: Routledge.

Hong, J. F. L., M. Easterby-Smith and R. S. Snell (2006). 'Transferring Organizational Learning Systems to Japanese Subsidiaries in China', Journal of Management Studies, 43: 1027-1058.

Howard-Grenville, J. A (2005) 'The Persistence of Flexible Organizational Routines: The Role of Agency and Organizational Context', Organization Science 16: 618-36.

Kogut, B. and U. Zander (1993) 'Knowledge of the Firm and the Evolutionary Theory of the Multinational Corporation', Journal of International Business Studies 24: 625-45.

Lave, J. (1993). 'The Practice of Learning', in S. Chaiklin and J. Lave (eds) Understanding Practice: Perspectives on Activity and Context, pp. 3-34. Cambridge: Cambridge University Press.

Lave, J. and Wenger, E. (1991) Situated Learning: Legitimate Peripheral Participation. Cambridge: Cambridge University Press.

Macharzina, K., Oesterle, M.-J. and Brodel, D. (2001) 'Learning in Multinationals', in M. Dierkes, A. B. Antal, J. Child and I. Nonaka (eds), Handbook of Organizational Learning and Knowledge, pp. 631-56. Oxford: Oxford University Press. 
Mill, J. S. (1974) A system of Logic Ratiocinative and Inductive: Being a Connected View of the Principles of Evidence and the Methods of Scientific Investigation. Toronto: University of Toronto Press.

Nicolini, D., Gherardi, S. and Yanow, D. (2003). Knowing in Organizations: A Practice-based Approach. Armonk: M. E. Sharpe.

Redding, G. (2005) 'The Thick Description and Comparison of Societal Systems of Capitalism', Journal of International Business Studies 36: 123-55.

Soekijad, M., Huis, Huis in't Veld, M. A. A. and Enserink, B. (2004). 'Learning and Knowledge Processes in Inter-Organizational Communities of Practice', Knowledge and Process Management, 11: 3-12.

Uhlenbruck, K., Meyer, K. E. and Hitt, M. A. (2003) 'Organizational Transformation in Transition Economies: Resource-based and Organizational Learning Perspectives', Journal of Management Studies 40: 257-82.

Vitols, S. (2001). "Varieties of Corporate Governance: Comparing Germany and the UK". In: P. A. Hall and D. Soskice (eds). Varieties of Capitalism: The Institutional Foundations of Comparative Advantage, 337-60. Oxford: Oxford University Press.

Wenger, E. (1998). Communities of Practice. Cambridge: Cambridge University Press.

Wever, K. S. (1995). "Human Resource Management and Organizational Strategies in Germanand US-Owned Companies”, International Journal of Human Resource Management, 6: 606-25.

Whitley, R. (1999). Divergent Capitalisms: The Social Structuring and Change of Business Systems. Oxford: Oxford University Press.

Yamin, O. J. (2004) 'Patterns of Knowledge Flows and MNE Innovative Performance', Journal of International Management 10: 239-58.

Zahra, S. A., Ireland, R. D. and Hitt, M. A. (2000) 'International Expansion by New Venture Firms: International Diversity, Mode of Market Entry, Technological Learning, and Performance', Academy of Management Journal 43: 925-950. 
Table 1. Case-study firms

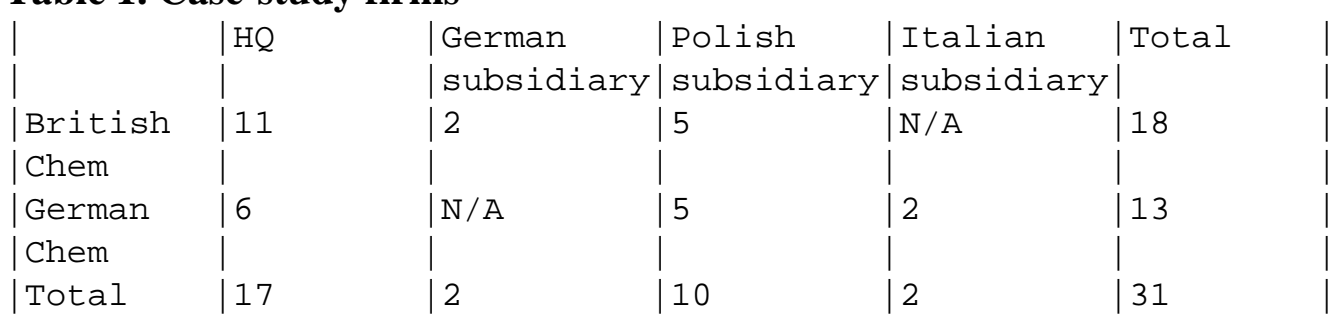




\section{Table 2. List of interviewees}

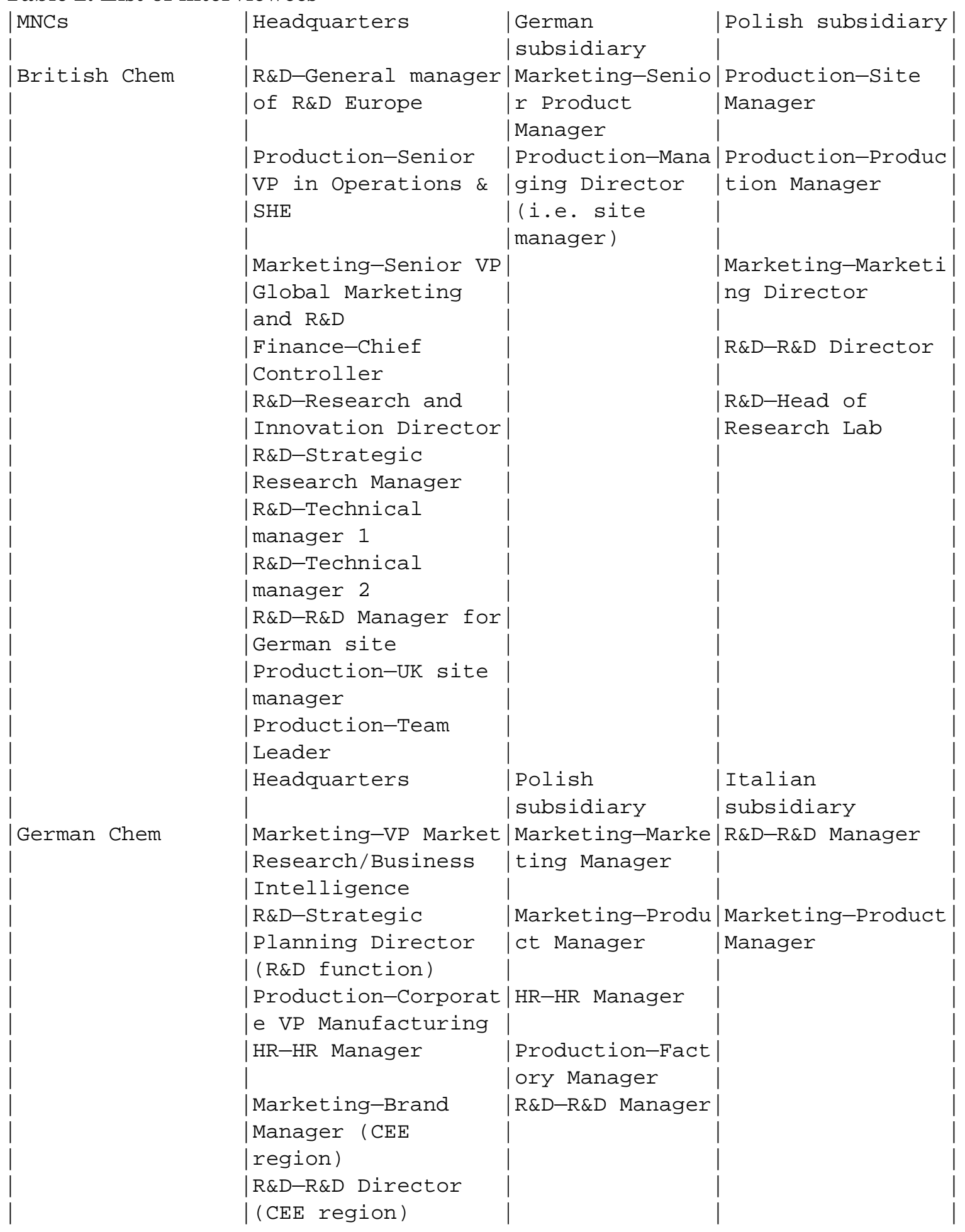




\section{Table 3. Patterns of learning at subsidiaries}

\begin{tabular}{|c|c|c|}
\hline $\mathrm{MNCS}$ & British Chem & German Chem \\
\hline $\begin{array}{l}\text { International-level } \\
\text { strategy }\end{array}$ & International & Mix of transnational \\
\hline $\begin{array}{l}\text { Coordination } \\
\text { structure }\end{array}$ & International & $\begin{array}{l}\text { Integrated network for } \\
\text { global form among the }\end{array}$ \\
\hline Knowledge transfer & $\begin{array}{l}\text { Exports product ideas and recipes, as well } \\
\text { as manufacturing process improvement } \\
\text { know-how }\end{array}$ & $\begin{array}{l}\text { Exports to and imports } \\
\text { formulations from WE o } \\
\text { | marketing knowledge an } \\
\text { | operations }\end{array}$ \\
\hline Subsidiaries & Germany & Poland \\
\hline $\begin{array}{l}\text { Mode of entry into } \\
\text { host country }\end{array}$ & Acquisition (1998) $\quad$ Acquisition (1996) & $\begin{array}{l}\text { Joint venture in 1931, } \\
\text { full ownership in } 1992\end{array}$ \\
\hline Mode of control & $\begin{array}{l}\text { Direct, impersonal: Standardized and } \\
\text { formalized new product development } \\
\text { procedures }\end{array}$ & $\begin{array}{l}\text { Direct, personal: } \\
\text { Centralised control } \\
\text { whereby decisions are } \\
\text { taken by the Austrian }\end{array}$ \\
\hline $\begin{array}{l}\text { Patterns of } \\
\text { learning }\end{array}$ & $\begin{array}{l}\text { One-way flow of } \\
\text { knowledge, } \\
\text { Iteration and } \\
\text { application }\end{array}$ & $\begin{array}{l}\text { One-way flow of } \\
\text { |knowledge, } \\
\text { Application }\end{array}$ \\
\hline
\end{tabular}


